\title{
Nitrogen-rich transition metal nitrides
}

\author{
Ashkan Salamat $^{[\mathrm{ad}]}$, Andrew L. Hector ${ }^{[\mathrm{b}]}$, Peter Kroll ${ }^{[\mathrm{c}]}$ and Paul F. McMillan ${ }^{[\mathrm{d}]}$
}

\begin{abstract}
The solid state chemistry leading to the synthesis and characterization of metal nitrides with N:M ratios $>1$ is summarized. Studies of these compounds represent an emerging area of research. Most transition metal nitrides have much lower nitrogen contents, and they often form with nonor sub-stoichiometric compositions. These materials are typically metallic with often superconducting properties, and they provide highly refractory, high hardness materials with many technological applications. The higher metal nitrides should achieve formal oxidation states (OS) attaining those found among corresponding oxides, and they are expected to have useful semiconducting properties. Only a very few examples of such high OS nitrogen-rich compounds are known at present. The main group elements typically form covalently bonded nitride ceramics such as $\mathrm{Si}_{3} \mathrm{~N}_{4}, \mathrm{Ge}_{3} \mathrm{~N}_{4}$ and $\mathrm{Sn}_{3} \mathrm{~N}_{4}$, and the early transition metals $\mathrm{Zr}$ and $\mathrm{Hf}$ produce $\mathrm{Zr}_{3} \mathrm{~N}_{4}$ and $\mathrm{Hf}_{3} \mathrm{~N}_{4}$. However, the only main example of a highly nitrided transition metal compound known to date is $\mathrm{Ta}_{3} \mathrm{~N}_{5}$, that has a formal oxidation state +5 and is a semiconductor with visible light absorption leading to applications as a pigment and in photocatalysis. New synthesis routes are being explored to study the possible formation of other $\mathrm{N}$-rich materials that are predicted to exist by $a b$ initio calculations. There is a useful interplay between theoretical predictions and experimental synthesis studies at ambient and high pressure conditions, as we explore and establish the existence and structure-property relations of these new nitride compounds and polymorphs. Here we review the state of current investigations and indicate possible new directions for further work.
\end{abstract}

\footnotetext{
${ }^{\text {[a] }}$ European Synchrotron Radiation Facility, BP 220, 38043 Grenoble, Cedex 9, France.

Current address: Lyman Laboratory of Physics, Harvard University, Cambridge, Massachusetts 02138, USA

Email address: salamat@physics.harvard.edu

${ }^{[b]}$ Chemistry, University of Southampton, Southampton SO17 1BJ, UK.

[c] Department of Chemistry and Biochemistry, The University of Texas at Arlington, Arlington, Texas, 760190065, USA.

${ }^{\text {[d] }}$ Department of Chemistry, University College London, London WC1H 0AJ, UK.
} 


\section{Introduction}

The solid state chemistry of transition metal nitrides is distinct from that of corresponding oxides. Nitride chemistry long remained a relatively neglected area of research, but intensive investigations throughout the past 30-40 years has greatly increased the number of known nitride compounds. However, although many new compounds and structure types have been discovered and characterized, the number of materials still remains limited relative to that of the oxides [1-3]. One of the main features of nitride chemistry is that the transition metals usually occur with lower formal oxidation states than are achieved among more ionic oxide or halides compounds, and the materials are often sub- or non-stoichiometric. For example, typical binary nitrides include $\mathrm{Cr}_{2} \mathrm{~N}, \mathrm{TiN}_{\mathrm{x}}(0.76<\mathrm{x}<1.1), \mathrm{Mo}_{2} \mathrm{~N}$ or MoN compared with the oxides $\mathrm{Cr}_{2} \mathrm{O}_{3}, \mathrm{TiO}_{2}$ and $\mathrm{MoO}_{3}$. Although the nitride structures often map on to those found among the oxides and halides, such as the cubic rocksalt structure found for $\operatorname{TiN}_{\mathrm{x}}$, the bonding in the nitrides is largely metallic with strong overlap between the metal atoms, and the $\mathrm{N}$ atoms are usually considered to occupy interstitial sites within the metal sublattice. These properties are shared by corresponding carbides such as TiC or WC and they lead to highly refractory, high hardness materials leading to their use as abrasives, structural cermets and protective coatings. They are typically superconducting and can achieve relatively high $\mathrm{T}_{\mathrm{c}}$ values (e.g. 15-18 $\mathrm{K}$ for NbN and MoN) and they provide conductive diffusion barrier layers for electronics devices. The optical properties lead to coloured coatings for costume jewellery, and they have applications in catalysis [4-13].

However, some nitrides and oxynitrides occur with the transition metals in higher oxidation states. The classic example is $\mathrm{Ta}_{3} \mathrm{~N}_{5}$ formed by ammonolysis and other reactions at ambient pressure conditions that provides a semiconductor used in pigments and which has potentially useful photocatalytic properties [14-16]. $\mathrm{Zr}$ and $\mathrm{Hf}$ typically form metallic mononitrides, but $\mathrm{Zr}_{3} \mathrm{~N}_{4}$ that can be prepared via chemical routes is a narrow gap semiconductor. A cubic polymorph as well as the first example of $\mathrm{Hf}_{3} \mathrm{~N}_{4}$ have also recently been produced using high pressure-high temperature combination of the elements (Table 1) [17]. Previously unknown nitrides such as $\mathrm{PtN}_{2}, \mathrm{IrN}_{2}, \mathrm{OsN}_{2}$ and $\mathrm{PdN}_{2}$ have also recently been obtained by this method (Table 1) [18-21]. Other higher nitrides as well as different crystalline polymorphs have been predicted to exist using $a b$ initio theoretical techniques [22-25]. Devising synthesis routes to these new phases and studying their properties and structural polymorphism is an active area of current research. Here we review a selection of these studies and indicate new areas to be developed.

\section{Synthesis of higher nitrides}

\subsection{General considerations}

Several factors contribute to the difficulty of synthesizing nitride compounds, and especially higher metal nitrides. The large bond enthalpy of the triply bonded $\mathrm{N}_{2}$ molecule $\left(946 \mathrm{~kJ} \mathrm{~mol}^{-1}\right.$ ) combined with its high ionization potential $\left(1505 \mathrm{~kJ} \mathrm{~mol}^{-1}\right)$ and the fact that the molecular bonding levels are completely filled makes this a generally unreactive element compared with oxygen or the halogens. Once a metal nitride is formed, however, it tends to form a highly refractory material due to intermetallic bonding contributions, although the enthalpy of formation of TiN $\left(-337 \mathrm{~kJ} \mathrm{~mol}^{-1}\right)$ is only around one third that of $\mathrm{TiO}_{2}$ [26]. In addition, the nitrides tend to react with $\mathrm{O}_{2}$ and $\mathrm{H}_{2} \mathrm{O}$ at high temperature, and oxynitrides can form readily during synthesis and processing. Hence considerable precautions need to be taken to exclude air and moisture from the apparatus and precursors. These considerations provide barriers to the experimental investigation of nitride solid state chemistry. Thermal stability is a further impediment to the exploration of higher nitrides. Although the binary nitrides of groups $4(\mathrm{Ti}, \mathrm{Zr}$, 
$\mathrm{Hf})$ and $5(\mathrm{~V}, \mathrm{Nb}, \mathrm{Ta})$ have extremely high thermal stability (e.g. HfN decomposes at $>3000{ }^{\circ} \mathrm{C}$ [27]), the thermal stability of nitrides (and similarly carbides) drops sharply at around group 6 ( $\mathrm{Cr}$, Mo, W) [28], and until recently no nitrides of the $4 d$ and $5 d$ metals of groups 7 to 12 were known at all. It is critically important to include both thermodynamic and kinetic considerations in any attempts at synthesis design.

\subsection{Ambient and low pressure synthesis approaches}

The simplest way to obtain a binary compound is to combine the constituent elements under a given set of $\mathrm{P}, \mathrm{T}$ conditions. Heating metals or samples mixed with carbon to high temperatures in $\mathrm{N}_{2}$ or $\mathrm{NH}_{3}$ environments and examining the recovered products has resulted in much of our current knowledge of transition metal nitride-carbide compounds and their phase relations [29, 30]. However, these techniques usually lead to formation of lower nitride materials.

Physical vapour deposition (PVD) and ion implantation techniques provide an important subset of elemental combination reaction schemes that result in thin films of materials including nitrides. Poorly crystalline, $\mathrm{N}$-rich $\mathrm{ZrN}_{\mathrm{x}}$ films with $\mathrm{x}$ up to 1.33 are reported [31] and some composition control can be achieved by varying the nitrogen partial pressure over which deposition takes place [32]. The cubic $\mathrm{Th}_{3} \mathrm{P}_{4}$-structured (I-43d) $\mathrm{c}-\mathrm{Zr}_{3} \mathrm{~N}_{4}$ phase that was originally discovered via high-P, $\mathrm{T}$ synthesis techniques (section 2.3) has now been produced as a thin film by filtered cathodic arc PVD [33] or radiofrequency sputtering of $\mathrm{Zr}$ under high purity $\mathrm{N}_{2}$ gas [34]. Important properties including the mechanical (critical stress, hardness) and electrical (resistivity, carrier concentration and Hall mobility) behaviour have been measured for the thin film. An important implication of this result is that new materials originally produced by synthesis under high-P, $T$ conditions may go on to be achieved metastably at low pressure in technologically useful forms such as thin films [35]. Niobium nitrides with $\mathrm{N}$-rich compositions up to $\mathrm{Nb}_{3} \mathrm{~N}_{4}$ have been produced by pulsed laser deposition of $\mathrm{Nb}$ in $\mathrm{N}_{2} / \mathrm{H}_{2}$ mixtures [36], $\mathrm{Ta}_{3} \mathrm{~N}_{5}$ films have been obtained by various PVD methods $[37,38]$ and $\mathrm{Ta}_{4} \mathrm{~N}_{5}$ has been obtained by reactive sputtering (Table 1) [39].

Reactions of thin metal films with ammonia have been used to prepare tetragonal $M_{4} N_{5}$ ( $M=N b$ [40], Ta [41] and $\mathrm{Mo}$ [42]) and hexagonal $\mathrm{M}_{5} \mathrm{~N}_{6}(\mathrm{M}=\mathrm{Nb}$ [40] and Ta [41]) compounds (Figure 1) (Table 1). The tetragonal phase forms a cation-defective $\mathrm{NaCl}$-type lattice with ordered vacancies, whereas the hexagonal structure has been described as an intergrowth between the WC- $(P-6 m 2)$ and NiAs-type $\left(P 6_{3} / \mathrm{mmc}\right)$ structures due to its $\mathrm{AABB}$... packing arrangement [43]. The layered hexagonal phases $W_{2.56} \mathrm{~N}_{4}$ and $W N_{2}$ have also been reported to occur from reactions of very thin W films with ammonia at $750{ }^{\circ} \mathrm{C}$ followed by quenching, although the compositions of these phases were only estimated from atom positions obtained from electron diffraction analysis and these materials have not yet been produced in bulk form $[44,45]$. 

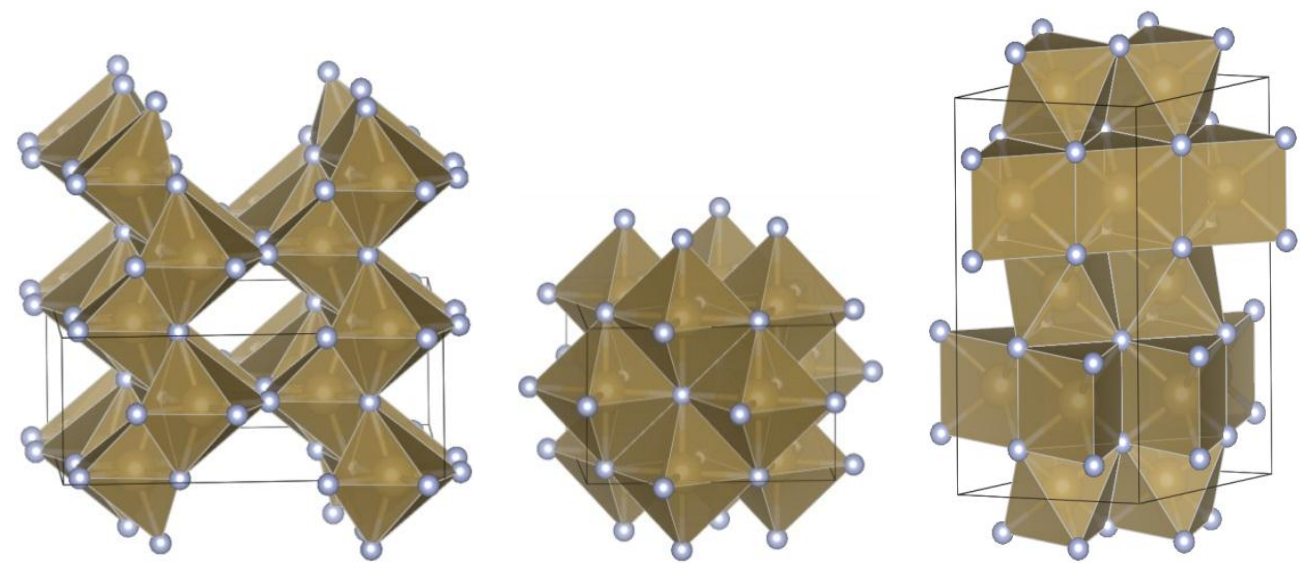

Figure 1: Edge-linked structures of $\mathrm{Ta}_{3} \mathrm{~N}_{5}$ (left, highly distorted $\mathrm{TaN}_{6}$ octahedra and open channels associated with the Ta vacancies), $\mathrm{Ta}_{4} \mathrm{~N}_{5}$ (centre, $\mathrm{TaN}_{6}$ octahedra with a Ta vacancy at the centre of the defective rocksalt unit cell) and $\mathrm{Ta}_{5} \mathrm{~N}_{6}$ (right, showing alternating hexagonal layers of $\mathrm{TaN}_{6}$ octahedra and trigonal prisms) $[46,47]$.

Chemical vapour deposition (CVD) and atomic layer deposition (ALD) techniques are well developed for metal nitride thin films. These techniques have been extensively investigated as fabrication methods for applications in microelectronics as well as protective coatings on metals and ceramics. Fix et al. reported crystalline $\mathrm{Zr}_{3} \mathrm{~N}_{4}$ and $\mathrm{Hf}_{3} \mathrm{~N}_{4}$ films in 1991, produced from tetrakis(diethylamido) complexes of the metals and ammonia under atmospheric pressure CVD conditions [48]. They also observed a small nitrogen excess in the TiN films deposited from $\mathrm{Ti}\left(\mathrm{NMe}_{2}\right)_{4}$. The diffraction data showed all to have very similar patterns to those of the rocksaltstructured mononitrides. In the TiN samples the lattice parameter was identical to that of bulk $\mathrm{TiN}$, whereas the $\mathrm{Zr}_{3} \mathrm{~N}_{4}$ and $\mathrm{Hf}_{3} \mathrm{~N}_{4}$ samples showed an increase in lattice parameter that was suggested to be combined with a small rhombohedral distortion and ascribed to partially-filled tetrahedral interstices.

There is a significant literature on the ALD synthesis of tantalum nitrides, including deposition of $\mathrm{Ta}_{3} \mathrm{~N}_{5}$ films from $\mathrm{TaCl}_{5}, \mathrm{Ta}\left(\mathrm{NMe}_{2}\right)_{5}$ or $\mathrm{Ta}\left(\mathrm{N}^{\mathrm{t}} \mathrm{Bu}\right)\left(\mathrm{NEt}_{2}\right)_{3}$ with $\mathrm{NH}_{3}$ [49]. Often these films are amorphous and a significant part of the research effort has been to avoid the formation of the higher Ta oxidation state to produce metallic compositions for use as barrier layers and conductive gate materials $[50,51]$. A novel nitrogen-rich tantalum nitride phase produced by plasma enhanced CVD from $\mathrm{TaCl}_{5}$ and nitrogen is $\mathrm{Ta}_{2} \mathrm{~N}_{3}$, which crystallises with a cubic $\mathrm{Mn}_{2} \mathrm{O}_{3^{-}}$ type ordered defect fluorite lattice [52]. This compound has now also been reported to occur from high-P, $T$ synthesis reactions between $T a$ and $\mathrm{N}_{2}[53]$.

Solid state metathesis reactions using a metal halide and a nitrogen source such as $\mathrm{Li}_{3} \mathrm{~N}$ or $\mathrm{NaN}_{3}$ provide a potential route to nitrogen-rich compositions as they often use halides that combine readily with the alkali to produce nitrides with the metal ions in high oxidation states. These reactions reach high temperature very rapidly and are also very rapidly quenched with the possibility of recovering metastable phases. As the thermal stability of the product is reduced (from group 6 onwards) it becomes more difficult to obtain samples of the metal nitride without an elemental metal contaminant present, as the synthesis $T$ approaches that of thermal decomposition. However, even with early transition metals these reactions usually lead to lower nitride compounds or elemental metals in combination with gaseous nitrogen [54-58], e.g.:

$$
3 \mathrm{TiCl}_{4}+4 \mathrm{Li}_{3} \mathrm{~N} \rightarrow 3 \mathrm{TiN}+12 \mathrm{LiCl}+1 / 2 \mathrm{~N}_{2}
$$


An exception to this general observation is the synthesis of $\mathrm{Ta}_{3} \mathrm{~N}_{5}$ formed by reacting solid $\mathrm{TaCl}_{5}$ with LiNMe ${ }_{2}$, although this reaction required subsequent annealing of the amorphous product in ammonia to yield a crystalline phase [59]. Use of similar reagent mixtures under solvothermal conditions is highly effective for controlling the distribution of thermal energy that is evolved rapidly throughout these highly exothermic reactions, and metal reduction occurs to a lesser extent. However, this is still dependent to a large extent on the inherent thermodynamic and kinetic stability of the product phases. $\mathrm{ZrCl}_{4}$ or $\mathrm{NbCl}_{5}$ react with $\mathrm{Na}_{3} \mathrm{~N}$ in supercritical benzene to produce the mononitrides $[60,61]$, as formed in the solid state reactions between these reagents [36]. However, the solvothermal reaction of $\mathrm{CrCl}_{3}$ with $\mathrm{Li}_{3} \mathrm{~N}$ yields $\mathrm{CrN}$ (decomposition temperature $\sim 925{ }^{\circ} \mathrm{C}[62]$ ), retaining significantly more nitrogen than the solid state reaction, which results in $\mathrm{Cr}$ metal and $\mathrm{Cr}_{2} \mathrm{~N}$ [34]. Similarly the solvothermal reactions of $\mathrm{MnCl}_{2}, \mathrm{FeCl}_{3}$ and $\mathrm{NiBr}_{2}$ yield $\mathrm{MnN}, \mathrm{Fe}_{2} \mathrm{~N}$ and $\mathrm{Ni}_{3} \mathrm{~N}$ [63] rather than $\mathrm{Mn}_{4} \mathrm{~N}$, Fe and $\mathrm{Ni}$ [36]. Only in the case of $\mathrm{Ta}_{3} \mathrm{~N}_{5}$ produced from $\mathrm{TaCl}_{5}$ and $\mathrm{LiNH}_{2}$ or ammonia has a truly high oxidation state, nitrogen-rich composition been produced under solvothermal conditions $[64,65]$. Interestingly, using ammonia as the nitriding agent high-aspect single-crystal nanorods of this phase were produced, Figure 2.

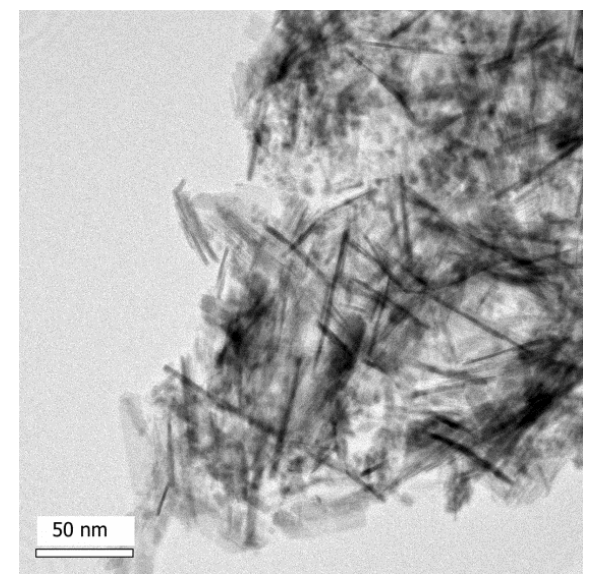

Figure 2: Transmission electron micrograph of $\mathrm{Ta}_{3} \mathrm{~N}_{5}$ nanorods grown from the solvothermal reaction in benzene of $\mathrm{TaCl}_{5}$ and ammonia at $550^{\circ} \mathrm{C}$.

Some higher transition metal nitride compounds can be produced by ammonolysis of a simple binary precursor. $\mathrm{Ta}_{3} \mathrm{~N}_{5}$ is readily produced by reaction of $\mathrm{TaCl}_{5}[66]$ or $\mathrm{Ta}_{2} \mathrm{O}_{5}[67,68]$ with $\mathrm{NH}_{3}$ at elevated temperature. $\mathrm{Ta}_{3} \mathrm{~N}_{5}$ has a pseudo-brookite $(\mathrm{Cmcm})$ structure containing irregular $\mathrm{TaN}_{6}$ octahedra linked by 3- and 4- coordinate nitrogen atoms (Figure 1). It is a useful orange-red pigment $[69,70]$ with an optical band gap of $2.1 \mathrm{eV}$, and its suggested applications for photocatalysis using visible light irradiation have been responsible for the recent growth in interest in this phase. Domen and co-workers initially reported a quantum efficiency of $\sim 10 \%$ for overall water splitting with good hydrolytic stability using this material [14]. Further work has examined potential improvements in its photocatalytic activity by high pressure ammonia treatment [71] or sodium doping [72], as well as its use to generate electrical currents in photoelectrochemical cells $[15,73]$.

Other nitrogen-rich transition metal-containing phases have so far mainly been a subject of intellectual curiosity, although they are predicted to have useful semiconducting, optical or chemical properties. A red-brown phase of $\mathrm{Zr}_{3} \mathrm{~N}_{4}$ is prepared by ammonolysis of $\mathrm{ZrCl}_{4}$ between 850 and $950{ }^{\circ} \mathrm{C}$ [74]. It has an orthorhombic $\mathrm{Eu}_{3} \mathrm{O}_{4}$-type (Pnam) structure with distorted octahedral and trigonal prismatic $\mathrm{ZrN}_{6}$ coordination polyhedra. In contrast to $\mathrm{Ta}_{3} \mathrm{~N}_{5}, \mathrm{Zr}_{3} \mathrm{~N}_{4}$ cannot be prepared by ammonolysis of the oxide [75]. $\mathrm{Mo}_{5} \mathrm{~N}_{6}$ can be produced by ammonolysis of $\mathrm{MoS}_{2}$ 
at $750{ }^{\circ} \mathrm{C}$. All these phases are stable up to $800{ }^{\circ} \mathrm{C}$ in inert atmospheres before their decomposition to the corresponding mononitrides $[54,56,75]$.

Various molecular precursors have been used to produce bulk metal nitride powders. Using urea as a nitrogen source with chloride- or alkoxide-based precursors leads to $\mathrm{TiN}, \mathrm{VN}, \mathrm{CrN}, \mathrm{Fe}_{2} \mathrm{~N}, \mathrm{Fe}_{3} \mathrm{~N}$, $\mathrm{NbN}, \mathrm{Mo}_{2} \mathrm{~N}, \mathrm{MoN}, \mathrm{W}_{2} \mathrm{~N}$ [76]. The only nitrogen-rich phase to have been produced in this way is $\mathrm{Ta}_{3} \mathrm{~N}_{5}$ [77]. The reaction of chlorides with ammonia in solution to form a chloride-imide polymer followed by heating in ammonia has produced TiN, VN and WN [78-80], but the reactions of $\mathrm{TaCl}_{5}$ yield $\mathrm{Ta}_{3} \mathrm{~N}_{5}$ and nitrogen-rich compositions can also be obtained from $\mathrm{NbCl}_{5}$ (up to $\mathrm{NbN}_{1.64}$ ) and from $\mathrm{MoCl}_{5}$ (with reported compositions up to $\mathrm{MoN}_{1.32}$ ) [81].

Similarly metal dialkylamides react with liquid ammonia to yield amide-imide polymers that may be pyrolysed to yield TiN, ZrN or NbN [82]. A detailed study by Chisholm and co-workers [83, 84] showed that such reactions yield polymers that generally have the same metal oxidation state as the starting amide. Recorded thermogravimetric (TGA) decomposition profiles often contained a plateau at around $\sim 400{ }^{\circ} \mathrm{C}$ that indicated formation of a nitrogen rich amorphous $\mathrm{M}_{3} \mathrm{~N}_{4}$ phase from amides containing $\mathrm{Ti}^{4+}, \mathrm{Zr}^{4+}, \mathrm{Hf}^{4+}, \mathrm{V}^{4+}, \mathrm{Nb}^{4+}$ or $\mathrm{Nb}^{5+}$, or $\mathrm{Ta}_{3} \mathrm{~N}_{5}$ where the amide was $\mathrm{Ta}\left(\mathrm{NMe}_{2}\right)_{5}$. All of these intermediate compounds lost further nitrogen at higher temperature, and only mononitride $\mathrm{MN}_{\mathrm{x}}(\mathrm{x} \sim 1)$ or lower phases were present in the final products [84]. No N-rich crystalline phases were observed to form for metallic elements in group 6 and above.

Reinvestigation of the amide-derived $\mathrm{TiN}_{\mathrm{x}}$ system showed that the $\mathrm{N}$-rich phase could actually contain significant carbon depending on the precursor used and subsequent annealing conditions. However, carrying out the ammonolysis reaction with $\mathrm{TiN}\left(\mathrm{Me}_{2}\right)_{4}$ and then heating in $\mathrm{NH}_{3}$ resulted in nearly pure $\mathrm{Ti}_{3} \mathrm{~N}_{4}$. The system, although mainly amorphous, contained 8-12 nm particles of TiN embedded within the amorphous matrix [85]. That result led to investigations of $\mathrm{TiN}_{\mathrm{x}} / \mathrm{a}-\mathrm{Ti}_{3} \mathrm{~N}_{4}$ nanocomposite materials [86]. The amorphous $\mathrm{Ti}_{3} \mathrm{~N}_{4}$ structure was studied using $\mathrm{X}$-ray absorption and EXAFS techniques that showed the local atomic configurations were based on the TiN rocksalt $(F m-3 m)$ structure, but with $40-50 \%$ vacancies on the cation and anion sites [85]. Similar products are obtained when titanium dialkylamides are reacted with primary amines then pyrolysed under ammonia [87, 88]. Reactions of $\mathrm{Zr}^{4+}$ and $\mathrm{Hf}^{4+}$ amides with ammonia did produce well defined $\mathrm{M}_{3} \mathrm{~N}_{4}$ phases, though these were poorly crystalline [89], and could contain nanoparticles embedded in an amorphous matrix as found for $\mathrm{Ti}_{3} \mathrm{~N}_{4}$. These analogous $\mathrm{Zr}$ and $\mathrm{Hf}$ nitrides have been shown to have broad peaks in their $\mathrm{X}$-ray diffraction patterns that have been suggested to be due to a rhombohedrally distorted rocksalt structure.

\subsection{High pressure synthesis approaches}

An important and emerging area in metal nitride chemistry is the application of high-P,T techniques in the synthesis and characterization of new phases, with an integrated approach that combines experimental and computational studies. Of all the current nitrides produced using high-P,T experiments most have exploited the high $\mathrm{N}_{2}$ thermodynamic activity (chemical potential) as a driving force for achieving synthesis. Because of its non-ideal properties, compressed fluid $\mathrm{N}_{2}$ generates much higher chemical potentials (i.e., fugacities) than expected from the applied pressure conditions, and contributes significantly to the synthesis reaction. This has been investigated theoretically by Kroll [90]. The laser-heated diamond anvil cell (LH-DAC) provides an ideal reaction chamber and is particularly useful as it allows structural studies of the new nitrides to be carried out using X-ray diffraction and optical spectroscopy, and recovery of the materials to ambient conditions can be followed in situ. The condensed nitrogen is introduced either as a cryogenic liquid or as a pressurized gas into DACs and can act as a pressure 
transmitting medium (PTM). In high-P, T experiments the use of a nitrogen PTM can stabilize nitride materials for studies under extreme conditions, and facilitate the formation of new structures [91-93]. It can also act as a reaction component in high-P,T synthesis experiments [17$20,53,91,94]$. Another high-P,T synthesis approach involves the use of large volume press (LVP) apparatus such as the multi-anvil, piston cylinder, Bridgman opposed anvil or "belt" press devices, or toroidal and Paris-Edinburgh cell designs. Here the $P, T$ conditions reached are generally less extreme than for LH-DAC studies, but larger sample quantities can be recovered.

A first example of using a high-P,T route was provided by $\mathrm{Si}_{3} \mathrm{~N}_{4}$ and $\mathrm{Ge}_{3} \mathrm{~N}_{4}$. At low pressure these form $a-$ and $b$ - polymorphs that have structures with tetrahedral covalent bonding of the group 14 elements. High-P, $T$ synthesis studies either reacting the elements or converting the low $P$ polymorphs resulted in formation of $\mathrm{g}-\mathrm{Si}_{3} \mathrm{~N}_{4}$ and $\mathrm{g}-\mathrm{Ge}_{3} \mathrm{~N}_{4}$ with a cubic spinel structure [91, 93, 94]. At the same time Scotti et al. reported cubic spinel $\mathrm{Sn}_{3} \mathrm{~N}_{4}$ [95] from ambient pressure chemical reactions between $\mathrm{Snl}_{4}$ or $\mathrm{SnBr}_{2}$ and $\mathrm{KNH}_{2}$. $\mathrm{Sn}_{3} \mathrm{~N}_{4}$ was later achieved at high pressure using a metathesis reaction [96]. The possibility now exists to develop new materials in the spinelstructured $\mathrm{g}-(\mathrm{Si}, \mathrm{Ge}, \mathrm{Sn})_{3} \mathrm{~N}_{4}$ and SiAION systems for electronic and structural ceramic applications [97-99].

Zerr et al. used the LH-DAC approach to synthesize high density polymorphs of $\mathrm{Zr}_{3} \mathrm{~N}_{4}$ and $\mathrm{Hf}_{3} \mathrm{~N}_{4}$ from the elements at 15.6 to $18 \mathrm{GPa}$ and at temperatures between 2,500 and 3,000 K [17]. No $\mathrm{Hf}_{3} \mathrm{~N}_{4}$ compound had been reported previously, but an orthorhombic form of $\mathrm{Zr}_{3} \mathrm{~N}_{4}$ was known from chemical synthesis at ambient pressure conditions (section 2.2) [74, 100]. The high pressure phases adopt the $\mathrm{Th}_{3} \mathrm{P}_{4}(I-43 d)$ structure with eight coordinate cations and six coordinate anions, and they are fully recoverable to ambient conditions. The unit cell parameters of the recovered materials are $\mathrm{a}_{0}=6.701 \AA$ for $\mathrm{c}-\mathrm{Hf}_{3} \mathrm{~N}_{4}$ and $6.740 \AA$ for $\mathrm{c}-\mathrm{Zr}_{3} \mathrm{~N}_{4}$ (Table 1). The bulk modulus values for both nitrides were initially estimated at $\mathrm{K}_{0}=250 \mathrm{GPa}$ although more recent measurements have found $\mathrm{K}_{0}=227(7)$ with $\mathrm{K}^{\prime}=5.3(6)$ for $\mathrm{c}-\mathrm{Hf}_{3} \mathrm{~N}_{4}$ [101]. Both compounds are narrow gap semiconductors with $\mathrm{c}-\mathrm{Hf}_{3} \mathrm{~N}_{4}$ exhibiting transparency to visible light in the red region of the spectrum, while $c-2 r_{3} \mathrm{~N}_{4}$ remains opaque. The Raman spectra of both phases are characterized by a dominant feature at $\sim 400 \mathrm{~cm}^{-1}$ between 16 and $18 \mathrm{GPa}$ [17].

Dzivenko et al. explored alternative routes to synthesis of group 4 nitrides using multi-anvil techniques to produce macroscopic quantities of the materials [102]. Direct reactions between the elements are not feasible in a large volume apparatus so these workers exploited the poorly crystalline $\mathrm{Zr}_{3} \mathrm{~N}_{4+x}$, synthesized by the ammonolysis of $\mathrm{Zr}\left(\mathrm{NEt}_{2}\right)_{4}$ [89], as their precursor and carried out experiments at $12 \mathrm{GPa}$ and $1900 \mathrm{~K}$. Electron microprobe analysis of the recovered sample revealed a small but significant oxygen content resulting in a composition of $Z_{2.86}\left(\mathrm{~N}_{0.88} \mathrm{O}_{0.12}\right)_{4}$. TEM examination did not reveal any amorphous oxide layer and it was concluded that the oxygen was incorporated into the crystal structure substituting for the nitrogen atoms. The structure type was the same $\mathrm{Th}_{3} \mathrm{P}_{4}$ type lattice found via the LH-DAC synthesis route, but with a slight increase in the lattice parameter to $a_{0}=6.7549 \AA$ when compared to $6.740 \AA$ for $c-Z_{3} \mathrm{~N}_{4}$ (Table 1). The introduction of oxygen requires the creation of vacancies on the cation sites that could be partly responsible for the slight lattice expansion. SEM reveals a porous surface that could be associated with $\mathrm{N}_{2}$ loss during the high-P, $\mathrm{T}$ synthesis experiments, and Vickers microhardness measurements reveal $\mathrm{H}_{v}=12.0$ (6) GPa, lower than found for the fully dense $c-\mathrm{Zr}_{3} \mathrm{~N}_{4}$ material $\left(\mathrm{H}_{\mathrm{v}}>30 \mathrm{GPa}\right.$ ) [33, 103]. Analogous synthesis attempts made with $\mathrm{Hf}_{3} \mathrm{~N}_{4}$ produced a mixture of crystalline $\mathrm{c}-\mathrm{Hf}_{3} \mathrm{~N}_{4}$ along with $\mathrm{HfO}_{2}$ and $\mathrm{HfON}$ phases [103].

Despite the success of the above approaches, the most revealing observation for nitride chemistry is that other predicted phases such as $\mathrm{Ti}_{3} \mathrm{~N}_{4}$ and $\mathrm{WN}_{2}$ cannot be prepared in this way, indicating that a more subtle approach combining chemical precursors with the high- $\mathrm{P}, \mathrm{T}$ synthesis is needed. 


\subsection{Theoretical predictions}

$A b$ initio or first principles calculations and structure prediction methods are playing an increasingly important role in the search for new nitrides. The most important studies have been carried out using density functional theoretical techniques (DFT) with the electron exchange and correlation approximated either within the Local Density Approximation (LDA) or the Generalized Gradient Approximation (GGA). Most studies employ pseudo-potentials and the expansion of the electronic wave function into a plane-wave basis set. GGA calculations are most useful to access relative enthalpies, while LDA calculations are typically better for vibrational and elastic properties. Optimizing all structural parameters and computing the enthalpy at various pressures can be very fast - within seconds - for simple structures without many degrees of freedom. However, studying materials with large unit cells or using supercells to study defective structures takes considerably more effort and can require access to large supercomputers or clusters.

A typical computational strategy is to investigate the relative stability of a series of candidate high pressure phases, although increasingly methods including random structure search and evolutionary algorithms are being applied to predict the structures of new high pressure phases [104-106]. In general, DFT calculations yield a quite accurate assessment of the relative enthalpies of different phases. When comparing ideal solid state structures of equal composition, examining enthalpy differences between the phases usually provides a sound estimate of thermodynamic stabilities and phase sequences, since contributions from the vibrational entropy are small and will be compensated by only a few GPa variation of pressure. Transition pressures obtained from enthalpy differences between phases usually fall within 2-3 GPa of experimental values. Larger deviations are generally indicative of strong entropy effects, presence and impact of defects, or possibly erroneous experimental data sets.

In searching for new nitrides, it is dangerous to infer "stability" of metal nitrogen compounds of different composition without explicitly including the thermodynamics of nitrogen at elevated temperatures. Reported enthalpy differences have their meaning only at zero Kelvin, and the often-inferred "stability" of a compound - and with it the likelihood of its synthesis - may only be valid at extreme low temperatures. In a series of papers, Kroll developed an approach to explicitly incorporate fugacity of nitrogen into thermochemical calculations of high-temperature, high-pressure phase stability of metal-nitrogen compounds [107-109]. As a rule of thumb, existing experimental data yields that at $1000 \mathrm{~K}$ and ambient pressure an additional $2 \mathrm{eV}$ per gaseous $\mathrm{N}_{2}$ molecule has to be taken into account to yield Gibbs energy differences. About a third of this needs to be considered at ambient temperature. Pressure reduces this effect, noticeably increasing fugacity of nitrogen. A full pressure-temperature dependency of fugacity, and how to include this in the assessment of stability of metal-nitrogen compounds is given by Kroll et al. [107].

\section{Structural characterization of higher nitrides}

\section{1 $\mathrm{Ti}_{3} \mathrm{~N}_{4}, \mathrm{Zr}_{3} \mathrm{~N}_{4}$ and $\mathrm{Hf}_{3} \mathrm{~N}_{4}$}

The adventitious discovery of spinel-structured polymorphs of the main group nitrides $\mathrm{Si}_{3} \mathrm{~N}_{4}$ and $\mathrm{Ge}_{3} \mathrm{~N}_{4}$ was described above. Theory predicts that analogous materials should also exist for $\mathrm{Ti}_{3} \mathrm{~N}_{4}$ and other transition metal nitride systems [110], with potentially useful electronic, structural and chemical properties $[23,24]$. However, none of these compounds have been prepared to date. Titanium lies just above $\mathrm{Zr}$ and $\mathrm{Hf}$ in group 4 of the periodic table, and it might be expected to show analogous behaviour to $\mathrm{Si}$ and $\mathrm{Ge}$. The stable oxide is $\mathrm{TiO}_{2}$ with formally +4 cations. 
However, all high-P,T synthesis studies to date have resulted in the mononitride $\operatorname{TiN}_{x}$ (with $x$ ranging between $0.76-1.05$ ) with a rocksalt structure and metallic properties [17].

Kroll investigated the relative stability of high pressure polymorphs for the $\mathrm{Hf}_{3} \mathrm{~N}_{4}, \mathrm{Zr}_{3} \mathrm{~N}_{4}$ and $\mathrm{Ti}_{3} \mathrm{~N}_{4}$ compositions using a DFT approach $[108,109]$. That work found the cubic $\mathrm{Th}_{3} \mathrm{P}_{4}$ structured polymorphs of $\mathrm{Hf}_{3} \mathrm{~N}_{4}$ and $\mathrm{Zr}_{3} \mathrm{~N}_{4}$ to be stabilized above 15-20 GPa relative to orthorhombic forms of these nitrides, as observed experimentally [17]. Both of these structures as well as a spinelstructured polymorph were predicted to occur in the 15-30 GPa range for $\mathrm{Ti}_{3} \mathrm{~N}_{4}$ [110]. The fact that these compounds have not been observed is thus not due to any intrinsic lack of stability, but likely that the very high density and exothermic heat of formation of the mononitride phase precludes its synthesis from the elements or via TiN $+\mathrm{N}_{2}$ reactions. Identifying viable routes to $\mathrm{Ti}_{3} \mathrm{~N}_{4}$ synthesis and recovery is important for creating a new generation of semiconducting materials comparable to $\mathrm{TiO}_{2}$, a system with important optoelectronic and photocatalysis properties [111-115].

An orthorhombic phase of $\mathrm{Zr}_{3} \mathrm{~N}_{4}$ was known from chemical synthesis studies at ambient $\mathrm{P}$ conditions, and a new high pressure cubic polymorph synthesized using high-P,T methods from the elements was described above (Figure 3). Previously no $\mathrm{Hf}_{3} \mathrm{~N}_{4}$ phase had been reported, but a cubic phase analogous to $\mathrm{Zr}_{3} \mathrm{~N}_{4}$ was found using the same LH-DAC technique [17].
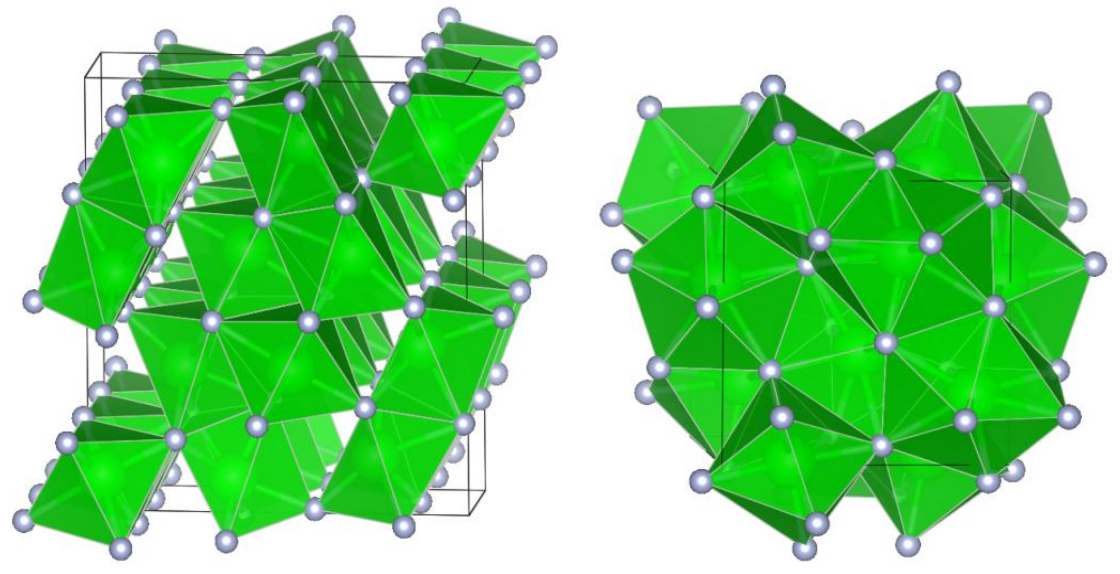

Figure 3: Structures of the orthorhombic (Pnam) $\mathrm{Zr}_{3} \mathrm{~N}_{4}$ structure synthesised at ambient pressure (left) showing face linked $\mathrm{ZrN}_{6}$ octahedra and trigonal prisms, and the cubic $\left(\mathrm{Th}_{3} \mathrm{P}_{4}\right.$-type (I-43d)) high pressure $\mathrm{Zr}_{3} \mathrm{~N}_{4}$ structure (right) showing face-linked $\mathrm{ZrN}_{8}$ distorted cubes.

\section{2 $\mathrm{Ta}_{3} \mathrm{~N}_{5}$}

Tantalum-nitrogen structures at ambient pressure range from solid solutions of nitrogen in closepacked tantalum to nitrogen-rich phases, including $\mathrm{Ta}_{3} \mathrm{~N}_{5}$ with tantalum in formal oxidation state +5 (Fig. 1). The high-pressure structural chemistry and properties of the mononitride TaN are developed experimentally and theoretically [116, 117]. e-TaN (CoSn-type $(P 6 / \mathrm{mmm})$ ) is the structure with lowest enthalpy and above $8 \mathrm{GPa}$ the J-TaN (WC-type $(P-6 m 2))$ becomes the stable structure stype $[107,117]$. In 2005, Kroll et al. predicted a new modification of $\mathrm{Ta}_{3} \mathrm{~N}_{5}$ with $\mathrm{U}_{3} \mathrm{Te}_{5}{ }^{-}$ type (Pnma) structure [107]. It comprises Ta in 8 -fold coordination and would be about $26 \%$ denser than the ambient pressure modification of $\mathrm{Ta}_{3} \mathrm{~N}_{5}$ with only 6 -fold coordinated Ta. It was predicted that this new $\mathrm{Ta}_{3} \mathrm{~N}_{5}-\mathrm{Il}$ phase may become accessible at pressures above 17-25 GPa at $2800 \mathrm{~K}$. 
High-P,T elemental combination experiments in the LH-DAC carried out by Zerr et al. yielded a new modification of $\mathrm{h}-\mathrm{Ta}_{2} \mathrm{~N}_{3}$, recoverable to ambient conditions, with a $\mathrm{U}_{2} \mathrm{~S}_{3}$-type $(P b n m)$ structure and Ta in 7-fold and 7+1-fold coordination [118, 119]. $\eta-\mathrm{Ta}_{2} \mathrm{~N}_{3}$ is obtained at high $\mathrm{P}$ conditions from $\mathrm{Ta}_{3} \mathrm{~N}_{5}$ by the decomposition reaction:

$$
2 \mathrm{Ta}_{3} \mathrm{~N}_{5} \rightarrow 3 \mathrm{Ta}_{2} \mathrm{~N}_{3}+1 / 2 \mathrm{~N}_{2}
$$

with a reduction in nitrogen content from $\operatorname{TaN}_{1.67}$ to $\mathrm{TaN}_{1.5}$. The synthesis was carried out using a Kawai-type multi-anvil apparatus with conditions up to a maximum of $20 \mathrm{GPa}$ and around $2000 \mathrm{~K}$ [118]. Subsequent computations by Jiang et al. showed that although the $U_{2} \mathrm{~S}_{3}$-type of $\mathrm{Ta}_{2} \mathrm{~N}_{3}$ is indeed a high-pressure phase of $\mathrm{Ta}_{2} \mathrm{~N}_{3}$ a candidate for the ground-state modification with a tetragonal anti- $\mathrm{Rh}_{3} \mathrm{P}_{2}$-type structure was found [120]. The tetragonal polymorph with all Ta atoms in 7 -fold coordination should exist up to $8 \mathrm{GPa}$, above which the $\mathrm{U}_{2} \mathrm{~S}_{3}$-type (with about $3 \%$ higher density) becomes more stable. The precise composition given by Zerr et al. using electron microprobe analysis of the sample synthesized at $11 \mathrm{GPa}$ recorded a final composition of $\mathrm{Ta}_{1.94}\left(\mathrm{~N}_{.95} \mathrm{O}_{.05}\right)_{3}$ [118]. Jiang et al. showed this oxygen contamination stabilizes the orthorhombic structure at low pressures [120], while Du et al. also indicated nitrogen deficiency as a possible stabilizing factor [121].

Further experimental investigations by Friedrich et al. confirmed the existence of $h-\mathrm{Ta}_{2} \mathrm{~N}_{3}$, but found no evidence of $\mathrm{Ta}_{3} \mathrm{~N}_{5}-\mathrm{II}$ in their series of high-pressure experiments up to $25 \mathrm{GPa}$ and 2000 $\mathrm{K}$ [53]. Recent calculations by Kroll et al. indicate that while the $\mathrm{U}_{2} \mathrm{~S}_{3}$-type of $\mathrm{Ta}_{2} \mathrm{~N}_{3}$ has a wide stability field, pressures higher than $40 \mathrm{GPa}$ might be needed to attain $\mathrm{Ta}_{3} \mathrm{~N}_{5}-\mathrm{Il}$ [120]. A phase diagram involving only $\mathrm{Ta}_{2} \mathrm{~N}_{3}$ and $\mathrm{Ta}_{3} \mathrm{~N}_{5}$ is given in Figure 4. It illustrates the phase boundary between of $h-T_{2} N_{3}$ and $T_{3} N_{5}-l l$ at high pressures and temperatures and incorporates the experimental conditions used by Friedrich et al.

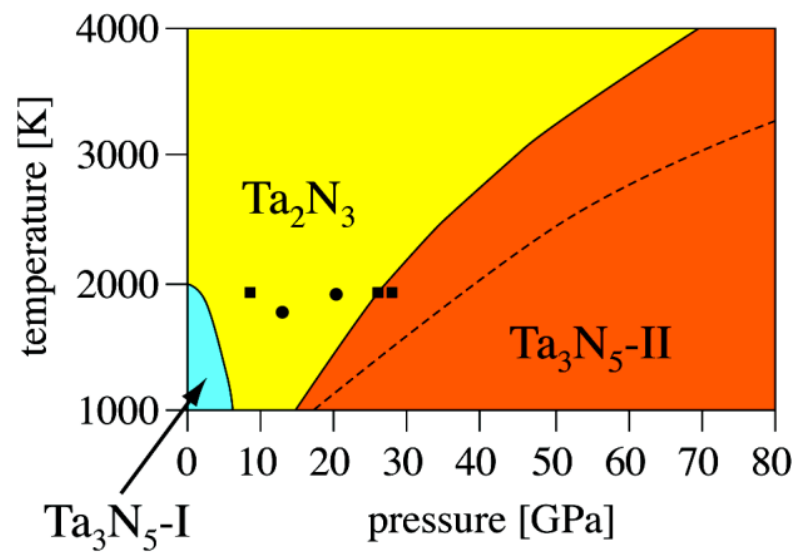

Figure 4: The calculated temperature-pressure phase diagram of $h-T_{2} N_{3}$ and $T a_{3} N_{5}-I$ and $-I I$. The experimental conditions of Friedrich et al. [53] are indicated by black dots. The solid lines refer to the "progressive" approximation for the fugacity of nitrogen, while the dashed line refers to the saturating formula proposed in Ref [107].

\subsection{New nitrides of the Pt group metals}

Unexpected reactivity is observed in the noble metals when heated in nitrogen at high pressure. Platinum [19, 122], osmium [20], iridium [19, 20] and palladium [21] form metal binary nitrides with stoichiometry $\mathrm{MN}_{\mathrm{x}>1}$ (Table 1). The first of these was reported by Gregoryanz et al. with the synthesis of binary platinum nitride by direct reaction between the elements above $45 \mathrm{GPa}$ in the 
LH-DAC [122]. They initially reported a 1:1 stoichiometry based on EDX analysis and a fcc lattice with $a=4.8 \AA$. Although from their diffraction data they could not distinguish between space groups $F 4-3 m$ and $F m-3 m$, they concluded that the first of these, the zinc blende structure, was best supported by their Raman spectroscopy data. A number of theoretical papers followed questioning the proposed structure and also the stoichiometry [123-125]. A repeat of the same experiment a few years later by Crowhurst et al. disputed the suggested stoichiometry and structure of the binary platinum nitride and proposed that the compound had a higher nitrogen content with stoichiometry $\mathrm{PtN}_{2}$ [19]. DFT calculations had previously showed that PtN with the zinc blende structure as initially proposed became less stable at higher pressure due to having a lower density than the constituent elements at the same given pressure. A pyrite structure with covalently bonded $\mathrm{N}_{2}$ units was then proposed (Figure 5) [19, 124, 126]. Interestingly, this structure contains anionic $\mathrm{N}_{2}$ units with bond lengths suggesting singly bonded species. That would then indicate the presence of $\left(\mathrm{N}_{2}\right)^{4-}$ anions with four electrons in the antibonding $\mathrm{p}_{\mathrm{g}}{ }^{*}$ orbitals, and hence a formal +4 state for the metal, although significant covalent interactions were found to be present [19].

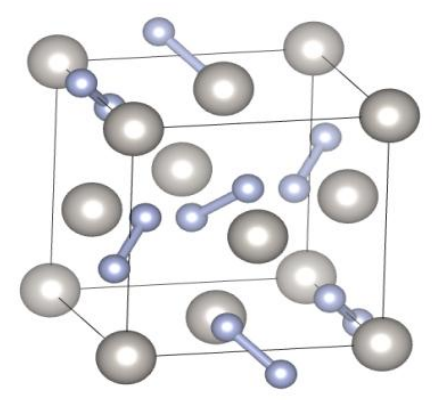

Figure 5: The pyrite $(\mathrm{Pa}-3)$ structure of $\mathrm{PtN}_{2}$ shown with $\mathrm{N}_{2}$ molecules.

The synthesis of $\operatorname{IrN}_{2}[19,20,127]$ and $\mathrm{OsN}_{2}$ [20] followed using direct laser heating of the elements at pressures around and above $50 \mathrm{GPa}$. In both cases there is experimental uncertainty regarding possible structure types of these systems as the reactions between the metal precursors and the nitrogen rich environment occur on the surface. This is shown by the relative intensities of the metal precursor to that of the respective nitride which in the case of $\mathrm{IrN}_{2}$ is 100:1 in respect to the metal to nitride ratio and therefore X-ray diffraction patterns are dominated by the unreacted bulk metal [19]. An additional complication that can be generalized to studies all of the noble metal nitrides is that the XRD patterns are mostly dictated by the heavy cations present in the unit cell and very little information can be obtained concerning the nitrogen positions or contributions to the diffraction intensities. This problem is exacerbated by the tiny sample sizes available from high-P,T synthesis experiments combined with poor powder diffraction statistics. Theoretical studies by $\mathrm{Yu}$ et al. and others suggest that possible solutions include a marcasite $(P n n m)$ structure type for $\mathrm{OsN}_{2}$ and a $\operatorname{CoSb}_{2}\left(P 2_{1} / c\right)$ structure type for $\operatorname{IrN}_{2}$, in close agreement with experimental diffraction data [20,21], as the most stable solutions within the experimental pressure range (Figure 6) [128]. This is confirmed by directly comparing the proposed crystal structures with the reported diffraction and Raman studies. Both $\operatorname{IrN} \mathrm{r}_{2}$ and $\mathrm{OsN}_{2}$ have extremely high bulk modulus values of $400 \pm 50 \mathrm{GPa}[20,128]$ and $>350 \mathrm{GPa}[20,128]$ respectively, that represent incompressibility values comparable to that of c-BN and diamond. The two structure types are closely related to each other and the marcasite structure is a parent space group of the $\mathrm{CoSb}_{2}$ structure that can be formed by a cell-doubling distortion. 

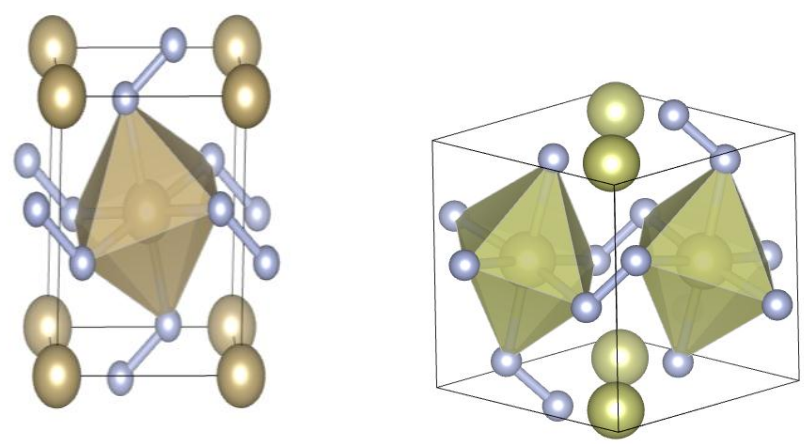

Figure 6: The crystal structures of the marcasite $(P n n m) \mathrm{OsN}_{2}$ (right) and that of the $\operatorname{CoSb}_{2}\left(P 2_{1} / c\right)$ $\mathrm{IrN}_{2}$ (left).

The most recent discovery of the noble metal nitrides is that of palladium nitride formed at higher pressures of above $58 \mathrm{GPa}$ although requiring much gentler heating, below $700{ }^{\circ} \mathrm{C}$ [21]. A nitrogen to metal stoichiometry of 2:1 with a pyrite structure was considered to have been achieved and this suggestion is supported by a theoretical calculation [129], giving rise to a similar structure to $\mathrm{PtN}_{2}$. Unlike the other noble nitrides this material is highly sensitive to conditions during decompression and is not recoverable below $13 \mathrm{GPa}$.

\subsection{W, Re and Ru nitrides}

The nitrogen-rich part of the $\mathrm{W}-\mathrm{N}$ phase diagram provides - currently - less variety than its Ta analogue. The most stable mononitride of WN adopts the NiAs-type $\left(P 6_{3} / m m c\right)$ structure, with the WC-type $(P-6 m 2)$ structure somewhat higher in energy [107]. In 2005, Kroll et al. provided an assessment of the high-temperature, high-pressure phase diagram of tungsten-nitrogen compounds [107]. In accordance with the general trend of coordination increase, it was predicted that at very high pressure tungsten adopts nine-fold coordination in a cotunnite-type (Pnma) $\mathrm{WN}_{2}$. The cotunnite structure exhibits isolated nitride ions, $\mathrm{N}^{3-}$, and, thus, tungsten adopts its highest possible oxidation state +6 .

Wang et al. corrected the predicted low-pressure phase sequence of $\mathrm{WN}_{2}$ [130]. They found that up to at least $60 \mathrm{GPa}$ two new structure candidates of $\mathrm{WN}_{2}$, both comprising pernitride units, $\mathrm{N}_{2}{ }^{4-}$, that are preferred in enthalpy. These structures can be viewed as NiAs-type and WC-type structures, respectively, with the pernitride unit occupying the anion position (Figure 7). Thus, W exhibits 6 -fold coordination by nitrogen and an oxidation state of +4 . Interestingly, both tungsten pernitride structures are predicted to be semiconductors. The Vickers hardness of the $\mathrm{WN}_{2}$ phases is predicted to be $36 \mathrm{GPa}$. This high value is attributed to the linkages between close-packed layers of $\mathrm{W}$ atoms via the single $\mathrm{N}-\mathrm{N}$ bond of the pernitride unit, which provides a strong resistance to shearing. However, hardness of pernitride $\mathrm{WN}_{2}$ will deteriorate at high pressures as found by Li et al. via inspection of its shear modulus at high pressure [131]. Additional tungstennitrogen compounds with compositions $\mathrm{WN}_{2}$ and $\mathrm{WN}_{3}$ have been predicted to exist theoretically by Song et al. [132]. 

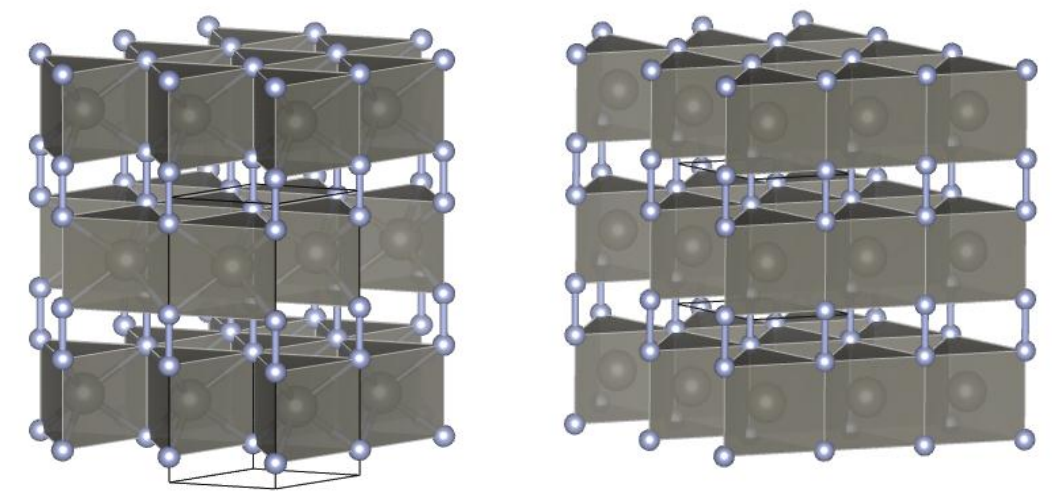

Figure 7: The NiAs-type hcp $\left(P 6_{3} / m m c\right.$, left) and the WC-type (P-6m2, right) structures of the hexagonal phases of $\mathrm{WN}_{2}$ predicted by Wang et al. [130] with $\mathrm{W}$ having 6 -fold coordination and an oxidation state of +4 .

There have been reports of varying $W N_{x}$ compositions prepared using thin film deposition routes although due to poor crystallinity their structures have not been characterized [133]. Most recently, Wang et al combined synthesis and computation studies to suggest two new phases of $W_{2} N_{3}$ and one of $W_{3} N_{4}$ (Table 1) [134]. The three new compounds were all reported to be produced at $5 \mathrm{GPa}$, but using different temperatures. The low-temperature $(880 \mathrm{~K})$ modification, rhombohedral $r-\mathrm{W}_{2} \mathrm{~N}_{3}(R 3)$, was characterized as an alternation of layers of edge-sharing $\mathrm{WN}_{6}$ octahedra and layers of edge-sharing $W N_{6}$ trigonal prisms. Between the alternating layers the polyhedra share faces. The octahedral W position is only $1 / 3$ occupied (Figure 8 (left)). The high temperature $(1223 \mathrm{~K})$ modification $\mathrm{h}-\mathrm{W}_{2} \mathrm{~N}_{3}\left(P 6_{3} / \mathrm{mmc}\right)$ comprises double layers of $\mathrm{WN}_{6}$ trigonal prisms alternating with one layer of $[\mathrm{v}] \mathrm{N}_{6}$ octahedra ([v] = vacancy) (Figure 8 (right)). In $\mathrm{W}_{2} \mathrm{~N}_{3}$ compounds tungsten adopts oxidation state of +4.5 , which is currently the highest for a binary W$\mathrm{N}$ compound. Confirmation of $\mathrm{NaBO}_{2}$ as a reaction by-product allowed for the solid state route to be identified:

$$
2 \mathrm{Na}_{2} \mathrm{WO}_{4}+4 \mathrm{BN} \rightarrow \mathrm{W}_{2} \mathrm{~N}_{3}+4 \mathrm{NaBO}_{2}+\frac{1}{2} \mathrm{~N}_{2}
$$

The bulk modulus of both $\mathrm{W}_{2} \mathrm{~N}_{3}$ polymorphs has been experimentally determined. Surprisingly, $\mathrm{K}_{\mathrm{o}}$ of $h-W_{2} N_{3}$ was suggested to be significantly larger than that for $r-W_{2} N_{3}$, i.e. 331 GPa versus 226 $\mathrm{GPa}$, respectively. Though the authors suggest that strong covalent $\mathrm{N}-\mathrm{N}$ bonds may be responsible for this observation, the reported structure data shows an interlayer distance between $\mathrm{N}$ atoms of $\sim 2.7 \AA$, which is far larger than a N-N bond distance. Maintaining the pressure at $5 \mathrm{GPa}$, but increasing the temperature to $2273 \mathrm{~K}$, leads to the decomposition of $\mathrm{h}-\mathrm{W}_{2} \mathrm{~N}_{3}$ to cubic c- $\mathrm{W}_{3} \mathrm{~N}_{4}(P m$ $3 \mathrm{~m}$ ), lowering of the nitrogen content from $W_{1.5}$ to $W N_{1.33} . W_{3} N_{4}$ is described as an ordered defective $\mathrm{CsCl}$-type structure with $1 / 4$ of cations (tungsten atoms) missing. When the temperature is further increased to $2570 \mathrm{~K}, \mathrm{~d}$-WN with the WC-type structure is obtained. The computed aggregate shear modulus of $c-W_{3} N_{4}$ is $183 \mathrm{GPa}$, which is quite high among the nitrogen-rich metal nitrogen compounds. Hence, it may be expected that $c-W_{3} \mathrm{~N}_{4}$ will exhibit a Vickers hardness greater than $40 \mathrm{GPa}$ [134]. 

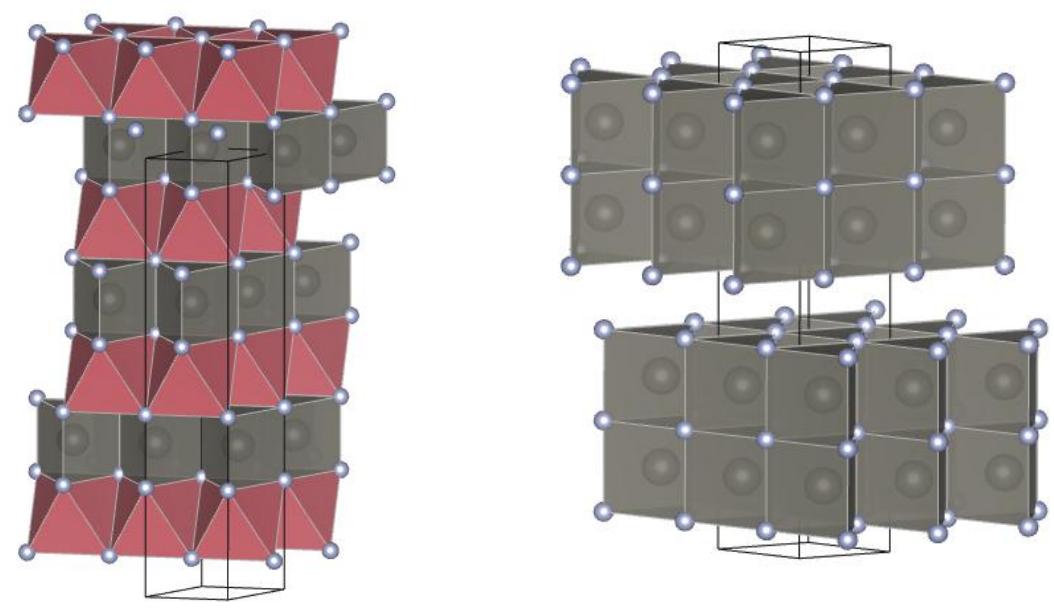

Figure 8: Structures of the $\mathrm{W}_{2} \mathrm{~N}_{3}$ systems both synthesized at $5 \mathrm{GPa}$ but at varying temperature. (left) Rhombohedral $(R 3) \mathrm{r}-\mathrm{W}_{2} \mathrm{~N}_{3}$ synthesized at $880 \mathrm{~K}$ with alternating layers of edge-sharing $\mathrm{WN}_{6}$ octahedra and layers of edge-sharing $\mathrm{WN}_{6}$ trigonal prisms. The octahedral $\mathrm{W}$ position is partially occupied to $1 / 3$. (right) Hexagonal $\left(P 6_{3} / \mathrm{mmc}\right) \mathrm{h}-\mathrm{W}_{2} \mathrm{~N}_{3}$ synthesized at $1223 \mathrm{~K}$ comprising of double layers of $\mathrm{WN}_{6}$ trigonal prisms alternating with one layer of [v] $\mathrm{N}_{6}$ octahedra ([v] = vacancy).

Kroll gave a first account of a phase diagram of Re-N compounds with high metal oxidation state [22]. For the mononitride ReN the lowest energy structure was predicted to adopt a cooperitetype structure with the metal cation in square-planar coordination to nitrogen. The NiAs-type with higher density rivals the cooperite in energy at zero pressure, but will be the most favorable structure of ReN for pressures above $6 \mathrm{GPa}$. Subsequently, the theoretical work by Li and Zeng reported elastic properties of the NiAs-type of ReN. Based on the computed bulk modulus of 450 GPa they estimated a hardness of $32 \mathrm{GPa}$ [135]. The lowest energy modification of the dinitride $\mathrm{ReN}_{2}$ was predicted by Kroll to adopt a columbite-type structure, but this was closely rivalled by a rutile-type modification [22]. Zhao and Wu studied the rutile modification of $\mathrm{ReN}_{2}$ [136]. They computed a negative enthalpy of formation for the structure and predicted its stability to up to 76 $\mathrm{GPa}$, beyond which a pernitride may be more favourable. Li and Zeng corroborated that an orthorhombic structure, isostructural to $\beta-\mathrm{ReO}_{2}$ type, to columbite, and to $\alpha-\mathrm{PbO}_{2}$, is indeed the ground state modification of $\mathrm{ReN}_{2}$ [137]. They also computed a bulk modulus for this structure to $331 \mathrm{GPa}$ and estimated a hardness of $17 \mathrm{GPa}$. Du et al. studied a structure derived from the CsCltype $(P m-3 m)$, with pernitride dumbbells occupying the anion positions [138]. They found remarkably high bulk and shear moduli for this structure, and estimated its hardness to be 46 GPa. They proposed that this tetragonal structure will be accessible in high-pressure experiments above $33 \mathrm{GPa}$. Kroll predicted a monoclinic $\operatorname{CoSb}_{2}$-type $\left(P 2_{1} / c\right)$ structure, also containing pernitride $\mathrm{N}_{2}{ }^{4-}$-units, as the thermodynamically most favourable modification of $\mathrm{ReN}_{2}$ at pressures exceeding $20 \mathrm{GPa}[22]$.

Many open and interesting questions remain concerning the Re-N phase system, that must be addressed by future experimental studies. All the computational studies appear to agree that a dinitride $\mathrm{ReN}_{2}$, with $\mathrm{Re}$ in oxidation state +6 , is favored at low pressure but this becomes energetically less favourable with respect to a pernitride $\mathrm{ReN}_{2}$ with $\mathrm{Re}$ in oxidation state +4 at higher pressures. This is a remarkable result, because we usually relate the increase of pressure to an increase in oxidation state of the metal cation. It is not yet clear if this predicted and counterintuitive behaviour of Re- $\mathrm{N}$ compounds is simply a consequence of the limited number of structures investigated theoretically, and experiments must be carried out to explore the problem further. Most recently, high-pressure experiments have suggested formation of a $\mathrm{ReN}_{2}$ compound with a $\mathrm{MoS}_{2}$ structure, with an unusually long axis length perpendicular to the layer plane [139]. 
Computational studies by Moreno-Armenta et al. have noted that ruthenium nitrides with $\mathrm{N}: \mathrm{Ru}$ ratios $>1: 4$ appear to be always metastable against dissociation into metallic $R u$ and $N_{2}$ [140]. This group also synthesized a mononitride RuN with $\mathrm{NaCl}$-type $(\mathrm{Fm}-3 \mathrm{~m})$ structure in ablation experiments and found it to be only marginable stable at ambient conditions. Subsequently, Yu et al. predicted theoretically a marcasite-type structure to be the lowest energy modification of $\operatorname{RuN}_{2}$ [141]. Due to the presence of the pernitride $\mathrm{N}_{2}{ }^{4-}$-unit, $\mathrm{Ru}$ adopts the oxidation state +4 in this structure. The low-pressure phase relations of $\mathrm{RuN}_{2}$ were adjusted by theoretical studies of $\mathrm{Li}$ et al, who found a new ground state structure for $\mathrm{P}<8 \mathrm{GPa}$ containing $\mathrm{N}=\mathrm{N}\left(\mathrm{N}_{2}{ }^{2-}\right)$ units, bridging between close-packed metal layers. Hence, a transition from the proposed ground state to the high-pressure marcasite phase would constitute an increase in the oxidation state of the metal cation from +2 to +4 . As to the possibility of a synthesis at high-pressure, high-temperature conditions, Kroll has showed that synthesis of $\mathrm{RuN}_{2}$ phases from the elements of would require pressures exceeding $30 \mathrm{GPa}$ at $\mathrm{T}>3000 \mathrm{~K}$ [22]. These predictions now await detailed highpressure experiments to investigate the formation of new series of Ru-N compounds and polymorphs.

\section{Summary and conclusions}

To date only a few synthesis studies either using chemical precursor approaches at ambient pressure or at high-P,T conditions have resulted in the formation of highly nitrided transition metal compounds and polymorphs, although such new phases are predicted to exist by first principles calculations. The known phases to date are listed in Table 1. The main barriers to these synthetic studies include the high thermodynamic stability and low reactivity of molecular $\mathrm{N}_{2}$ in its gaseous or fluid state, combined with the large exothermic formation enthalpy and high density of the mono- or lower nitride materials. High-P,T synthesis techniques or chemical routes involving precursors have resulted in the synthesis and recovery of several such new higher nitride phases, but this remains an active field for future study.

Table 1: Crystal structures of experimentally confirmed nitrogen rich transition metal nitrides

\begin{tabular}{|c|c|c|c|}
\hline Compound & Space group & Lattice parameters / $\AA$ & References \\
\hline $\mathrm{Zr}_{3} \mathrm{~N}_{4}$ & $\begin{array}{l}\text { Pnam } \\
\text { (No. 62) }\end{array}$ & $\begin{array}{l}a=9.788 \\
b=10.854 \\
c=3.300\end{array}$ & {$[74,100]$} \\
\hline$c-\mathrm{Zr}_{3} \mathrm{~N}_{4}$ & $\begin{array}{l}\text { l-43d } \\
\text { (No. 220) }\end{array}$ & $a=6.740$ & [17] \\
\hline $\mathrm{Zr}_{2.86}\left(\mathrm{~N}_{0.88} \mathrm{O}_{0.12}\right)_{4}$ & $\begin{array}{l}l-43 d \\
\text { (No. 220) }\end{array}$ & $a=6.7549$ & [102] \\
\hline $\mathrm{c}-\mathrm{Hf}_{3} \mathrm{~N}_{4}$ & $\begin{array}{l}\text { I-43d } \\
\text { (No. 220) }\end{array}$ & $a=6.701$ & [17] \\
\hline $\mathrm{Nb}_{4} \mathrm{~N}_{5}$ & $\begin{array}{l}14 / m \\
\text { (No. 87) }\end{array}$ & $\begin{array}{l}a=6.853 \\
c=4.270\end{array}$ & [40] \\
\hline $\mathrm{Nb}_{5} \mathrm{~N}_{6}$ & $\begin{array}{l}\mathrm{PG}_{3} / \mathrm{mcm} \\
\text { (No. 193) }\end{array}$ & $\begin{array}{l}a=5.193 \\
c=10.38\end{array}$ & {$[40]$} \\
\hline
\end{tabular}




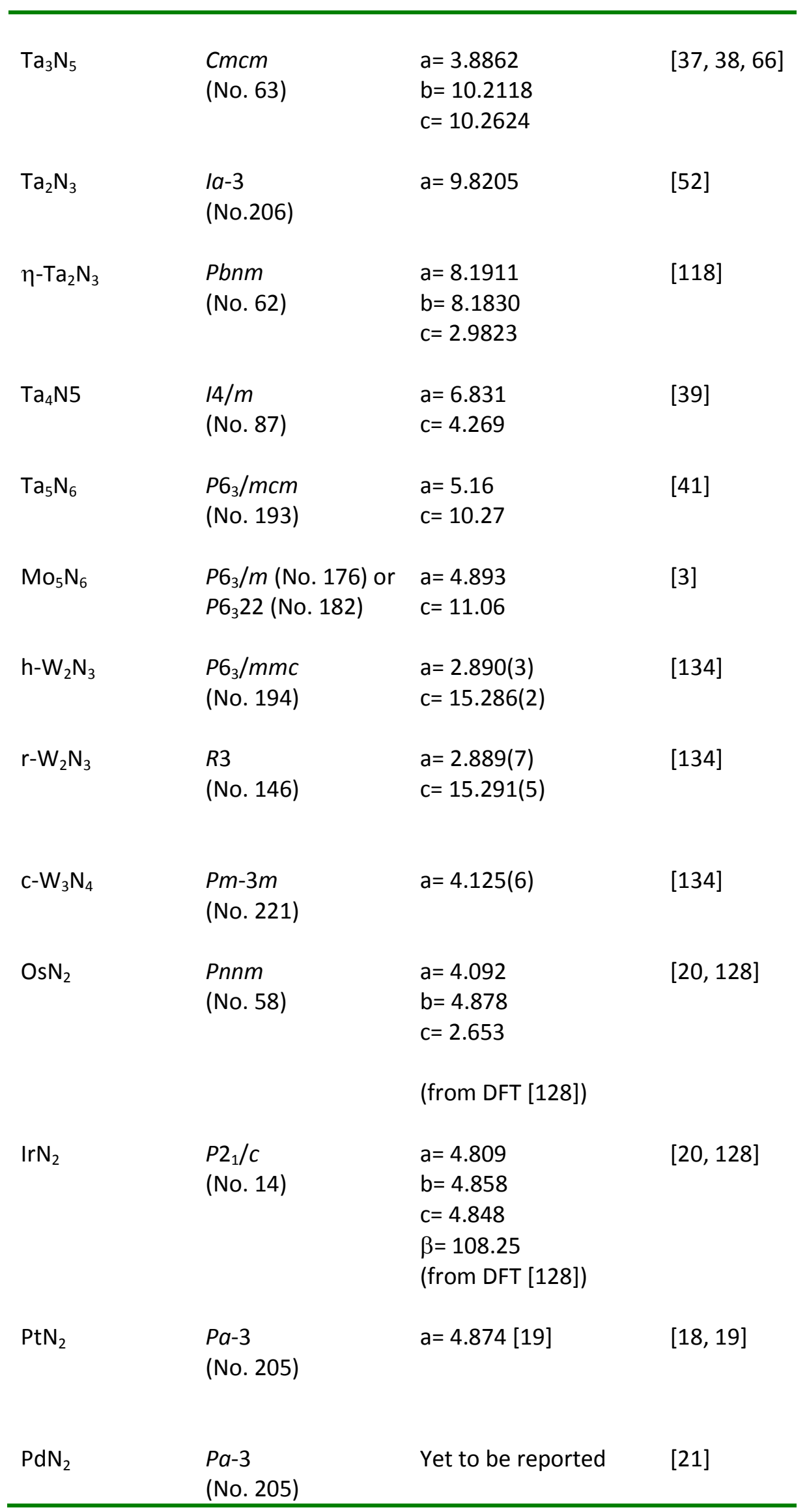




\section{Acknowledgements}

The work by PFM and ALH on high-pressure and precursor-based synthesis of nitrides has been supported by EPSRC and by the Royal Society.

\section{References}

[1] N. Brese, M. O'Keeffe, Crystal chemistry of inorganic nitrides

Complexes, Clusters and Crystal Chemistry, in, Springer Berlin / Heidelberg 1992, pp. 307-378.

[2] W. Schnick, Angew. Chem. Int. Ed. Engl. 32 (1993) 806-818.

[3] R. Marchand, F. Tessier, F. J. DiSalvo, J. Mater. Chem. 9 (1999) 297-304.

[4] W. Schintlmeister, O. Pacher, J. Vac. Sci. Technol. 12 (1970) 743.

[5] H.E. Hintermann, Thin Solid Films 84 (1981) 215-243.

[6] S.R. Kurtz, R.G. Gordon, Sol. Energ. Mat. 15 (1987) 229-236.

[7] A.J. Perry, M. Georgson, W.D. Sproul, Thin Solid Films 157 (1988) 255-265.

[8] G.I. Grigorov, K.G. Grigorov, M. Stoyanova, J.L. Vignes, J.P. Langeron, P. Denjean, Appl. Phys. A Mater. Sci. Process 57 (1993) 195-197.

[9] H. Hämmerle, K. Kobuch, K. Kohler, W. Nisch, H. Sachs, M. Stelzle, Biomaterials 23 (2002) 797804.

[10] M. Birkholz, K.E. Ehwald, D. Wolansky, I. Costina, C. Baristiran-Kaynak, M. Fröhlich, H. Beyer, A. Kapp, F. Lisdat, Surf. Coat Technol. 204 (2010) 2055-2059.

[11] M. Birkholz, K.E. Ehwald, P. Kulse, J. Drews, M. Fröhlich, U. Haak, M. Kaynak, E. Matthus, K. Schulz, D. Wolansky, Adv. Funct. Mater. 21 (2011) 1652-1656.

[12] J.S.J. Hargreaves, D. McKay, Royal Society of Chemistry, Spivey, J.J. (ed.) Catalysis. Series: Specialist Periodical Reports 19 (2006).

[13] D. McKay, D.H. Gregory, J.S.J. Hargreaves, S.M. Hunter, X. Sun, Chem. Commun. 29 (2007) 3051-3053.

[14] G. Hitoki, A. Ishikawa, T. Takata, J.N. Kondo, M. Hara, K. Domen, Chem. Lett. 31 (2002) 736737.

[15] A. Ishikawa, T. Takata, J.N. Kondo, M. Hara, K. Domen, J Phys. Chem. B 108 (2004) 1104911053.

[16] D. Yokoyama, H. Hashiguchi, K. Maeda, T. Minegishi, T. Takata, R. Abe, J. Kubota, K. Domen, Thin Solid Films 519 (2011) 2087-2092.

[17] A. Zerr, G. Miehe, R. Riedel, Nat. Mater. 2 (2003) 185-189.

[18] E. Gregoryanz, C. Sanloup, M. Somayazulu, J. Badro, G. Fiquet, H.K. Mao, R.J. Hemley, Nat. Mater. 3 (2004) 294-297.

[19] J.C. Crowhurst, A.F. Goncharov, B. Sadigh, C.L. Evans, P.G. Morrall, J.L. Ferreira, A.J. Nelson, Science 311 (2006) 1275-1278.

[20] A.F. Young, C. Sanloup, E. Gregoryanz, S. Scandolo, R.J. Hemley, H.-k. Mao, Phys. Rev. Lett. 96 (2006) 155501.

[21] J.C. Crowhurst, A.F. Goncharov, B. Sadigh, J.M. Zaug, D. Aberg, Y. Meng, V.B. Prakapenka, J. Mater. Res. 23 (2008) 1-5.

[22] P. Kroll, Nitrides and Related Bulk Materials, 1040 (2008).

[23] W.Y. Ching, S.D. Mo, L. Ouyang, I. Tanaka, M. Yoshiya, Phys. Rev. B 61 (2000) 10609.

[24] J.E. Lowther, M. Amkreutz, T. Frauenheim, E. Kroke, R. Riedel, Phys. Rev. B 68 (2003) 033201.

[25] C. Stampfl, C.G. Van de Walle, Phys. Rev. B 59 (1999) 5521-5535.

[26] G.L. Humphrey, J. Am. Chem. Soc. 73 (1951) 2261-2263.

[27] Handbook of Chemistry and Physics, 55th Edition, CRC Press, (1974). 
[28] H.A. Johansen, in Survey of Progress in Chemistry 8, A. Scott (Ed.), Academic Press, New York, (1977).

[29] L.E. Toth, Transition Metal Carbides and Nitride (Academic, New York), (1971).

[30] S. Ramanathan, S.T. Oyama, J. Phys. Chem. 99 (1995) 16365-16372.

[31] R. Lamni, E. Martinez, S.G. Springer, R. Sanjinés, P.E. Schmid, F. Lévy, Thin Solid Films 447, (2004) 316-321.

[32] A. Rizzo, M.A. Signore, L. Mirenghi, E. Serra, Thin Solid Films 515 (2006) 1307-1313.

[33] M. Chhowalla, H.E. Unalan, Nat. Mater. 4 (2005) 317-322.

[34] Y.R. Sui, Y. Xu, B. Yao, L. Xiao, B. Liu, Appl. Surf. Sci. 255 (2009) 6355-6358.

[35] P.F. McMillan, Nat. Mater. 1 (2002) 19-25.

[36] R.E. Treece, J.S. Horwitz, D.B. Chrisey, E.P. Donovan, S.B. Qadri, Chem. Mater. 6 (1994) 22052207.

[37] K. Radhakrishnan, N. Geok Ing, R. Gopalakrishnan, Mater. Sci. Eng. B 57 (1999) 224-227.

[38] S.K. Kim, B.C. Cha, Thin Solid Films 475 (2005) 202-207.

[39] D.-k. Kim, H. Lee, D. Kim, Y. Keun Kim, J. Cryst. Growth 283 (2005) 404-408.

[40] N. Terao, J. Less-Common Met. 23 (1971) 159-169.

[41] A. Fontbonne, J. C. Gilles, Rev. Intl. Hautes Tempr. Refract. 6 (1969) 181.

[42] N. V. Troitskaya, Z. G. Pinsker, Kristallografiya 8 (1963) 548.

[43] A.Y. Ganin, L. Kienle, G.V. Vajenine, J. Solid State Chem. 179 (2006) 2339-2348.

[44] V. I. Khitrova, Kristallografiya 6 (1961) 549.

[45] V. I. Khitrova, Kristallografiya 8 (1963) 39.

[46] D.A. Fletcher, R.F. McMeeking, D. Parkin, J. Chem. Inf. Comput. Sci. 36 (1996) 746-749.

[47] K. Momma, F. Izumi, J. Appl. Crystallogr. 44 1272-1276.

[48] R. Fix, R.G. Gordon, D.M. Hoffman, Chem. Mater. 3 (1991) 1138-1148.

[49] M. Ritala, P. Kalsi, D. Riihelä, K. Kukli, M. Leskelä, J. Jokinen, Chem. Mater. 11 (1999) 17121718.

[50] J. D. Kwon, J. S. Park, H. C. Lee, S. W. Kang, Electrochem. Solid State Lett. 9 (2006) G282.

[51] E. Langereis, H.C.M. Knoops, A.J.M. Mackus, F. Roozeboom, M.C.M. van de Sanden, W.M.M. Kessels, J. Appl. Phys. 102 (2007) 083517-083511.

[52] A.Y. Ganin, L. Kienle, G.V. Vajenine, Eur. J. Inorg. Chem. (2004) 3233-3239.

[53] A. Friedrich, B. Winkler, L. Bayarjargal, E.A.J. Arellano, W. Morgenroth, J. Biehler, F. Schroder, J.Y. Yan, S.M. Clark, J. Alloys Compd. 502 (2010) 5-12.

[54] A. Hector, I.P. Parkin, J. Chem. Soc. Chem. Commun. (1993) 1095-1096.

[55] E.G. Gillan, R.B. Kaner, Inorg. Chem. 33 (1994) 5693-5700.

[56] A.L. Hector, I.P. Parkin, Chem. Mater. 7 (1995) 1728-1733.

[57] J.C. Fitzmaurice, A.L. Hector, I.P. Parkin, J. Chem. Soc. Dalton Trans. (1993) 2435-2438.

[58] A.L. Hector, I.P. Parkin, Polyhedron, 14 (1995) 913-917.

[59] I.P. Parkin, A.T. Rowley, J. Mater. Chem. 5 (1995) 909-912.

[60] J. Hu, Q. Lu, K. Tang, B. Deng, R. Jiang, Y. Qian, G. Zhou, X. Liu, Chem. Lett. 29 (2000) 74-75.

[61] J. Ma, Y. Du, Y. Qian, J. Alloys Compd. 389 (2005) 296-298.

[62] W. Ernst, J. Neidhardt, H. Willmann, B. Sartory, P.H. Mayrhofer, C. Mitterer, Thin Solid Films

517 (2008) 568-574.

[63] J. Choi, E.G. Gillan, Inorg. Chem. 48 (2009) 4470-4477.

[64] B. Mazumder, P. Chirico, A.L. Hector, Inorg. Chem. 47 (2008) 9684-9690.

[65] P. Chirico, A.L. Hector, B. Mazumder, Dalton Trans. 39 (2010) 6092-6097.

[66] N.E. Brese, M. O'Keeffe, P. Rauch, F.J. DiSalvo, Acta Crystallogr. C 47 (1991) 2291-2294.

[67] G. Brauer, J. R. Weidlein, Angew. Chem. 77 (1965) 218.

[68] S.J. Henderson, A.L. Hector, J. Solid State Chem. 179 (2006) 3518-3524.

[69] E. Guenther, M. Jansen, Mater. Res. Bull. 36 (2001) 1399-1405.

[70] M. Jansen, E. Guenther, H.P. Letschert, German patent 19907 618.9, (1999). 
[71] Y. Lee, K. Nukumizu, T. Watanabe, T. Takata, M. Hara, M. Yoshimura, K. Domen, Chem. Lett. 35 (2006) 352-353.

[72] Y. Kado, R. Hahn, C.-Y. Lee, P. Schmuki, Electrochem. Commun. 17 (2012) 67-70.

[73] M. Higashi, K. Domen, R. Abe, Energy Environ. Sci. 4 (2011) 4138-4147.

[74] M. Lerch, E. Fuglein, J. Wrba, Z. Anorg. Allg. Chem. 622 (1996) 367-372.

[75] S.J. Clarke, C.W. Michie, M.J. Rosseinsky, J. Solid State Chem. 146 (1999) 399-405.

[76] Y. Qiu, L. Gao, J. Am. Ceram. Soc. 87 (2004) 352-357.

[77] Q. Gao, C. Giordano, M. Antonietti, Small, 7 (2011) 3334-3340.

[78] D.W. Choi, P.N. Kumta, Electrochem. Sol. St. Lett. 8 (2005) A418.

[79] D. Choi, P.N. Kumta, J. Am. Ceram. Soc. 88 (2005) 2030-2035.

[80] D. Choi, P.N. Kumta, J. Am. Ceram. Soc. 90 (2007) 3113-3120.

[81] D. Choi, P.N. Kumta, J. Am. Ceram. Soc. 94 (2011) 2371-2378.

[82] G.M. Brown, L. Maya, J. Am. Ceram. Soc. 71 (1988) 78-82.

[83] M.H. Chisholm, G.J. Gama, I.P. Parkin, V.F. Distasi, D.V. Baxter, Abstr. Pap. Am. Chem. Soc. 206 (1993) 160.

[84] D.V. Baxter, M.H. Chisholm, G.J. Gama, V.F. DiStasi, A.L. Hector, I.P. Parkin, Chem. Mater. 8 (1996) 1222-1228.

[85] A.W. Jackson, O. Shebanova, A.L. Hector, P.F. McMillan, J. Solid State Chem. 179 (2006) 13831393.

[86] E. Bailey, N.M.T. Ray, A.L. Hector, P. Crozier, W.T. Petuskey, P.F. McMillan, Materials 4 (2011) 1747-1762.

[87] A.W. Jackson, A.L. Hector, J. Mater. Chem. 17 (2007) 1016-1022.

[88] B.M. Gray, S. Hassan, A.L. Hector, A. Kalaji, B. Mazumder, Chem. Mater. 21 (2009) 4210-4215.

[89] J. Li, D. Dzivenko, A. Zerr, C. Fasel, Y. Zhou, R. Riedel, Z. Anorg. Allg. Chem., 631 (2005) 14491455.

[90] P. Kroll, Advances in computation of temperature-pressure phase diagrams of high-pressure nitrides, in: Siaions and Non-Oxides, Trans Tech Publications Ltd, Stafa-Zurich, 2009, pp. 77-80.

[91] A. Zerr, G. Miehe, G. Serghiou, M. Schwarz, E. Kroke, R. Riedel, H. Fuess, P. Kroll, R. Boehler, Nature 400 (1999) 340-342.

[92] B. Xu, J.J. Dong, P.F. McMillan, O. Shebanova, A. Salamat, Phy. Rev. B 84 (2011) 16.

[93] K. Leinenweber, M. O'Keeffe, M. Somayazulu, H. Hubert, P.F. McMillan, G.H. Wolf, Chem. Eur. J. 5 (1999) 3076-3080.

[94] G. Serghiou, G. Miehe, O. Tschauner, A. Zerr, R. Boehler, J. Chem. Phys. 111 (1999) 46594662.

[95] N. Scotti, W. Kockelmann, J. Senker, S. Traßel, H. Jacobs, Z. Anorg. Allg. Chem. 625 (1999) 1435-1439.

[96] M.P. Shemkunas, G.H. Wolf, K. Leinenweber, W.T. Petuskey, J. Am. Ceram. Soc. 85 (2002) 101-104.

[97] B. Molina, L.E. Sansores, Int. J. Quantum Chem. 80 (2000) 249-257.

[98] R.J. Xie, N. Hirosaki, Sci. Tech. Adv. Mater. 8 (2007) 588.

[99] W.Y. Ching, P. Rulis, Phy. Rev. B 73 (2006) 045202.

[100] W.H. Baur, M. Lerch, Z. Anorg. Allg. Chem. 622 (1996) 1729-1730.

[101] D.A. Dzivenko, A. Zerr, R. Boehler, R. Riedel, Solid State Commun. 139 (2006) 255-258.

[102] D.A. Dzivenko, A. Zerr, V.K. Bulatov, G. Miehe, J.W. Li, B. Thybusch, J. Brotz, H. Fuess, G. Brey, R. Riedel, Adv. Mater. 19 (2007) 1869.

[103] D.A. Dzivenko, A. Zerr, G. Miehe, R. Riedel, J. Alloys Compd. 480 (2009) 46-49.

[104] S.J. Clark, M.D. Segall, C.J. Pickard, P.J. Hasnip, M.J. Probert, K. Refson, M.C. Payne, Z. Kristall. 220 (2005) 567-570.

[105] D.C. Lonie, E. Zurek, Comput. Phys. Commun. 182 (2011) 372-387.

[106] A.R. Oganov, A.O. Lyakhov, M. Valle, Acc. Chem. Res. 44 (2011) 227-237.

[107] P. Kroll, T. Schroter, M. Peters, Angew. Chem.-Int. Edit. 44 (2005) 4249-4254. 
[108] P. Kroll, Phys. Rev. Lett. 20 (2003) 125501.

[109] P. Kroll, J. Phys. Condens. Matter 16 (2004) S1235.

[110] P. Kroll, Phys. Rev. Lett. 90 (2003) 4.

[111] A.L. Linsebigler, G. Lu, J.T. Yates, Chem. Rev. 95 (1995) 735-758.

[112] Y. Kuroda, T. Mori, K. Yagi, N. Makihata, Y. Kawahara, M. Nagao, S. Kittaka, Langmuir 21 (2005) 8026-8034.

[113] K. Maeda, K. Domen, J. Phys. Chem. C 111 (2007) 7851-7861.

[114] J. Sato, N. Saito, Y. Yamada, K. Maeda, T. Takata, J.N. Kondo, M. Hara, H. Kobayashi, K. Domen, Y. Inoue, J. Am. Chem. Soc. 127 (2005) 4150-4151.

[115] S.G. Ebbinghaus, H.-P. Abicht, R. Dronskowski, T. M,ller, A. Reller, A. Weidenkaff, Prog. Solid State Ch. 37 (2009) 173-205.

[116] E. Soignard, O. Shebanova, P.F.McMillan, Phys. Rev. B 75 (2007) 014104.

[117] E.J. Zhao, B. Hong, J. Meng, Z.J. Wu, J. Comput. Chem. 30 (2009) 2358-2363.

[118] A. Zerr, G. Miehe, J.W. Li, D.A. Dzivenko, V.K. Bulatov, H. Hofer, N. Bolfan-Casanova, M. Fialin, G. Brey, T. Watanabe, M. Yoshimura, Adv. Funct. Mater. 19 (2009) 2282-2288.

[119] S. Dever, P. Kroll, Report for the Welch Summer Program, UT Arlington, TX., (2011).

[120] C. Jiang, Z.J. Lin, Y.S. Zhao, Phys. Rev. Lett. 103 (2009) 185501.

[121] X.P. Du, Y.X. Wang, V.C. Lo, J. Phys. Chem. C 115 (2011) 3129-3135.

[122] E. Gregoryanz, C. Sanloup, M. Somayazulu, J. Badro, G. Fiquet, H.-k. Mao, R.J. Hemley, Nat. Mater. 3 (2004) 294-297.

[123] R. Yu, X.F. Zhang, Appl. Phys. Lett. 86 (2005) 121913.

[124] R. Yu, Q. Zhan, X.F. Zhang, Appl. Phys. Lett. 88 (2006) 051913.

[125] J. von Appen, M.-W. Lumey, R. Dronskowski, Angew. Chem. Int. Ed. 45 (2006) 4365-4368.

[126] A.F. Young, J.A. Montoya, C. Sanloup, M. Lazzeri, E. Gregoryanz, S. Scandolo, Phys. Rev. B 73 (2006) 153102.

[127] A.F. Goncharov, J.C. Crowhurst, J. Low Temp. Phys. 139 (2005) 727-737.

[128] R. Yu, Q. Zhan, L.C. De Jonghe, Angew. Chem. Int. Ed. 46 (2007) 1136-1140.

[129] W. Chen, J.S. Tse, J.Z. Jiang, J. Phys: Condens. Matter 22 (2010) 015404.

[130] H. Wang, Q. Li, Y.E. Li, Y. Xu, T. Cui, A.R. Oganov, Y.M. Ma, Phys. Rev. B 79 (2009).

[131] X.F. Li, Z.L. Liu, C.L. Ding, H.Z. Fu, G.F. Ji, Mater. Chem. Phys. 130 (2011) 14-19.

[132] L. Song, Y.X. Wang, Phys. Status Solidi B-Basic Solid State Phys. 247 (2010) 54-58.

[133] H.A. Wriedt, Bulletin of Alloy Phase Diagrams, 10 (1989) 358-367.

[134] S. Wang, X. Yu, Z. Lin, R. Zhang, D. He, J. Qin, J. Zhu, J. Han, L. Wang, H.-k. Mao, J. Zhang, Y. Zhao, Chem. Mater. 24 (2012) 3023-3028.

[135] Y.L. Li, Z. Zeng, Solid State Commun. 149 (2009) 1591-1595.

[136] E. Zhao, Z.J. Wu, Comp. Mater. Sci. 44 (2008) 531-535.

[137] Y.L. Li, Z. Zeng, Chem. Phys. Lett. 474 (2009) 93-96.

[138] X.P. Du, Y.X. Wang, V.C. Lo, Phys. Lett. A 374 (2010) 2569-2574.

[139] F. Kawamura, H. Yusa, T. Taniguchi, Appl. Phys. Lett. 100 (2012).

[140] M.G. Moreno-Armenta, J. Diaz, A. Martinez-Ruiz, G. Soto, J. Phys. Chem. Solids 68 (2007) 1989-1994.

[141] R. Yu, Q. Zhan, L.C. De Jonghe, Angew. Chem.-Int. Edit. 46 (2007) 1136-1140. 